\title{
Evaluation of the SERM
}

\section{Ormeloxifene in the Treatment of Uterine Fibroid in the Reproductive Age Group}

\section{Keywords: Ormeloxifene; SERMs; Fibroid; PBAC score \\ Abstract}

Background: The search for the ideal drug for medical treatment of fibroids is on. SERMs appear to be novel agents for hormonal manipulations. Ormeloxifene with biweekly dosing and minimum side effects needs evaluation for the above.

Method: The study was a prospective clinical observation undertaken to evaluate the efficacy of ormeloxifene in uterine fibroid in reproductive age group. Forty four (44) women aged 20-50 year age group who attended the outpatient gynaecology department diagnosed with fibroid uterus; symptomatic or asymptomatic were recruited for the study. Ormeloxifene $60 \mathrm{mg}$ was given orally twice a week for 6 months. Follow up was done at monthly interval and at the end of 6 months clinically and by USG. The primary outcome measures were fibroid size, uterine size and delta size. Secondary outcomes were measurement of menstrual blood loss using the PBAC score, hemoglobin concentration and endometrial thickness.

Results: No significant changes were observed in the leiomyoma uterine and delta size. $90.9 \%$ fibroids remained unchanged at the end of 6 months. The difference in mean hemoglobin concentration PBAC scores and endometrial thickness were statistically significant $(p<0.001)$. Hysterectomy was required in $5(11.36 \%)$ cases.

Conclusion: Ormeloxifene does not reduce fibroid size but prevents further growth of the tumour and significantly reduces menstrual blood loss in standard doses with minimum side effects for a short period of time.

\section{Introduction}

Uterine leiomyomas are the most common benign uterine tumours affecting around $20-25 \%$ women in the fertile age group [1]. The pathogenesis of the tumour is still not well understood. Hence, medical management of this condition is still in its nascent stage making surgery-(myomectomy or hysterectomy) the treatment of choice.

It has now been postulated that a genetic mutation leading to an alteration of intra- tumorogenic estrogen metabolism might be responsible in the pathogenesis. There is an increased transcription and expression of Estrogen Receptors (ER) in the myoma as compared to normal myometrium. Progesterone receptors have also been demonstrated in myomas [2-4].

Thus both estrogen and progesterone play an important role in tumor growth and maintenance $[2,3,5,6]$ and it is intuitive to assume that therapeutic hormonal manipulation affecting estrogen and progesterone may be effective in medical management of fibroids.

Many drugs such as Oral Contraceptive Pills (OCPs) [7,8] gestrinone [9], danazol [10], mifepristone [11,12], ulipristal [13]

\section{Journal of}

Syndromes

\begin{abstract}
Mandira Dasgupta*, Binpi Karlo, Rimik Biswas, Tarashankar Bag, Shyamali Dutta, Dipa Mallick and Tarun Kumar Sarkar
\end{abstract}

Department of Obstetrics and Gynecology, Medical College Kolkata, Calcutta University, Kolkata, West Bengal, India

\section{*Address for Correspondence}

Mandira Dasgupta, MD, DNB (G\&O), Department of Obstetrics and Gynecology, Medical College Medical College Kolkata, Calcutta University, Kolkata, West Bengal, India, Tel: +91 9831106193; E-mail: mandiradasgupta@hotmail.com

\section{Submission: 06 July, 2016 \\ Accepted: 19 July, 2016}

Published: 25 July, 2016

Copyright: (๑ 2016 Dasgupta M, et al. This is an open access article distributed under the Creative Commons Attribution License, which permits unrestricted use, distribution, and reproduction in any medium, provided the original work is properly cited.

Reviewed \& Approved by: Dr. Wei-Hsiung Yang, Mercer University School of Medicine, USA

and GnRH analogues $[14,15]$ have been tried in clinical trials. But, despite achieving a modest reduction of fibroid size and clinical improvements in menorrhagia and dysmenorrhoea, these have not become popular. This is due to different disadvantages of the agents used such as need for daily use of OCPs, severe side effects of gestrinone and danazol, endometrial hyperplasia of prolonged use of mifepristone or ulipristal [14] and occurrence of menopausal symptoms and bone loss in GnRH analogues which have to be used parenterally. Therefore these drugs are conventionally not considered for first line of management of leiomyomas.

Selective Estrogen Receptor Modulators (SERMS) that selectively bind to estrogen receptors and act as estrogen agonists in some tissues and estrogen antagonists in others seem an attractive agent for medical management of fibroids.

Preclinical studies [16] have confirmed that SERMS (tamoxifen, raloxifene) reduce myoma size by $40-60 \%$ in rats. Clinical studies $[11,17,18]$ have also shown that raloxifene significantly reduces mean uterine and leiomyoma size.

These initial success reports prompted the use of another SERMormeloxifene in uterine leiomyomas. This drug has already been approved for use as a contraceptive pill [19] and in treatment of menorrhagia [20]. Its role in uterine fibroids is yet to be explored [21]. Ormeloxifene is a third generation SERM which antagonizes the effect of estrogen on uterine and breast tissue and stimulates its effect on vagina, bone, cardiovascular and central nervous system [22]. Thus, when used in perimenopausal women it does not cause uterine stimulation, prevents bone loss, does not increase the risk of breast cancer, lowers cholesterol level and maintains cognitive function of the brain. It has the additional advantage of reducing premenstrual symptoms, mastalgia and dysmenorrhea. It is cheap with a long half-life, allowing biweekly/weekly dosing. It has minimum side effects [23] in the form of nausea, dyspepsia and rarely cystic ovaries. Ormeloxifene has an edge over raloxifene (the commonest SERM studied so far in fibroids) in having a longer half-life allowing a less 
Citation: Dasgupta M, Karlo B, Biswas R, Bag T, Dutta S. Evaluation of the SERM Ormeloxifene in the Treatment of Uterine Fibroid in the Reproductive Age Group. J Syndromes. 2016;3(1): 5.

frequent dosing schedule, having a better metabolic control and in the absence of the distressing antiestrogenic effects such as hot flushes and vaginal dryness. Thus, ormeloxifene is possibly useful in fibroids with good tolerability.

The primary objective of our study was to evaluate changes if any in the size of the leiomyoma following treatment with ormeloxifene. The secondary objectives were to study its effect on menorrhagia.

\section{Methods}

This is a prospective study of 24 weeks duration on 44 women with uterine fibroid, who attended the out-patient department of Obstetrics \& Gynaecology Medical College, Kolkata over a period of one year from June 2012 to May 2013.

After getting approval from the Institutional Ethics Committee, healthy women between 20-50 years of age with single or multiple fibroids were included consecutively in the study if they were symptomatic (menorrhagia, dysmenorrhoea, abdominal lump, dull aching lower abdominal pain, dyspareunia) or if the largest fibroid was $>5 \mathrm{~cm}$ on ultrasound.

Exclusion criteria were malignancies, metabolic, haematological, renal or liver diseases, more than $20 \mathrm{wk}$ gravid uterine size, fibroids $>15 \mathrm{~cm}$ by ultrasound, grade- 0 fibroids, suspected adenomyosis, current genital infection, endometrial hyperplasia with atypia, hormonal medication within 3 months, women desiring pregnancy and hypersensitivity to the drug.

After taking informed consent all the women were prescribed ormeloxifene $60 \mathrm{mg}$ twice a week for 6 months, after which they were re-evaluated. During the study, all women agreed to use barrier contraception. Follow up was done at 3 months and 6 months or earlier if necessary.

The primary outcome measures were fibroid size, uterine size, delta size and endometrial thickness. Secondary outcomes assessed were endometrial thickness, menstrual blood loss (PBAC score) and hemoglobin concentration.

Table 1: The age and parity distribution of the subjects $(n=44)$.

\begin{tabular}{|l|l|l|}
\hline Age & number & $\%$ \\
\hline Yrs & 4 & 9.09 \\
\hline $20-24$ & 6 & 13.64 \\
\hline $30-29$ & 12 & 27.27 \\
\hline $35-39$ & 11 & 25 \\
\hline $40-44$ & 9 & 20.45 \\
\hline $45-50$ & 2 & 4.54 \\
\hline Parity & & \\
\hline 0 & 2 & 4.55 \\
\hline 1 & 16 & 36.36 \\
\hline 2 & 15 & 34.09 \\
\hline 3 & 9 & 20.45 \\
\hline$\geq 4$ & 2 & 4.55 \\
\hline
\end{tabular}



Figure 1: Flow chart showing the flow of patients

The demographic and baseline clinical profile including details of menstrual cycle, symptoms and their severity were noted. Menstrual blood loss was assessed by Pictorial Blood Loss Assessment Chart (PBAC scores) [24], which is a semi quantitative assessment that takes into account the number of pads soaked, their degree of soakage, passage of clots and episodes of flooding. A score of 100 or more amounts to menorrhagia.

A complete general and gynaecological examination was done. Blood testing was done for haemoglobin, liver and kidney function tests.

USG was performed at the beginning of the study and after 6 months of treatment to ascertain uterine and leiomyoma size, number of tumors, endometrial thickness and also to exclude other pelvic pathologies. Uterine and fibroid volume was calculated by the ellipsoid method with the formula $\mathrm{V}=0.5233(\mathrm{D} 1 \mathrm{xD} 2 \mathrm{xD} 3)$ [25], where D1, D2 and D3 were the longitudinal, transverse and cross-sectional diameters respectively. Volume of each myoma was calculated and summation of all myomas was used in cases with multiple myomas. To evaluate the effect of ormeloxifene on the myometrium, the difference between uterine and leiomyoma volumes i.e. delta size $(\Delta)$ [25] was calculated in each subject. Endometrium was measured by the double endometrial thickness excluding the fluid in endometrial cavity.

On the basis of a previous study [26] the sample size was calculated to be of 30 subjects to detect an effect on the size of 1 sd with an a value of 0.05 (two-sided) and a power $1-\delta$ of 0.8 .

Statistical analysis was performed using the SPSS 9.0 package. Data were expressed as mean $\pm s d$. Paired t test was used to evaluate differences between uterine and leiomyoma sizes, $\Delta$ size, endometrial thickness, PBAC scores and haemoglobin levels at entry and after six months of treatment. The difference between the two proportions of the nominal data was analyzed by Z-test. P value $<0.05$ was considered statistically significant. 
Citation: Dasgupta M, Karlo B, Biswas R, Bag T, Dutta S. Evaluation of the SERM Ormeloxifene in the Treatment of Uterine Fibroid in the Reproductive Age Group. J Syndromes. 2016;3(1): 5.

ISSN: $2380-6036$

Table 2: Characteristics and Clinical presentation of the fibroids.

\begin{tabular}{|c|c|c|}
\hline Fibroid characteristics & Number $(n=44)$ & Percentage \\
\hline \multicolumn{3}{|l|}{ Number } \\
\hline 1 & 33 & $75 \%$ \\
\hline 2 & 8 & $18.18 \%$ \\
\hline$\geq 3$ & 3 & $6.82 \%$ \\
\hline \multicolumn{3}{|l|}{ Location } \\
\hline Intramural & 35 & $79.55 \%$ \\
\hline Subserous & 6 & $13.64 \%$ \\
\hline Submucous & 3 & $6.82 \%$ \\
\hline \multicolumn{3}{|l|}{ Symptoms } \\
\hline Asymptomatic & 5 & $11.36 \%$ \\
\hline Menstrual abnormalities & 34 & $77.27 \%$ \\
\hline Lower abdominal pain & 5 & $11.36 \%$ \\
\hline
\end{tabular}

Table 3: Outcome of treatment with ormeloxifene for 6 months.

\begin{tabular}{|l|l|l|l|l|}
\hline $\begin{array}{l}\text { S I } \\
\text { no }\end{array}$ & Outcome parameter & Pre treatment & $\begin{array}{l}\text { Post treatment } \\
(\mathbf{6} \text { months) }\end{array}$ & P value \\
\hline 1. & $\begin{array}{l}\text { Fibroid vol }\left(\mathrm{cm}^{3}\right) \\
\text { Mean (range) }\end{array}$ & $\begin{array}{l}22.81 \\
(1.14-208.7)\end{array}$ & $\begin{array}{l}25.69 \\
(1.22-250.59)\end{array}$ & 0.074 \\
\hline 2. & $\begin{array}{l}\text { Uterine vol }\left(\mathrm{cm}^{3}\right) \\
\text { Mean } \pm \text { SD }\end{array}$ & $269.65 \pm 153.20$ & $279.47 \pm 170.44$ & 0.054 \\
\hline 3. & $\begin{array}{l}\text { Delta size } \\
\text { Range }\end{array}$ & $\begin{array}{l}246.84 \pm 133.68 \\
(28.87-537.1)\end{array}$ & $\begin{array}{l}253.78 \pm 144.08 \\
(28.87-540.36)\end{array}$ & 0.06 \\
\hline 4. & $\begin{array}{l}\text { Endometrial Thickness } \\
(\text { mm) } \\
\text { Mean } \pm S D\end{array}$ & $7.99 \pm 1.16$ & $7.12 \pm 1.15$ & $\mathbf{P}<\mathbf{0 . 0 0 1}$ \\
\hline 5. & $\begin{array}{l}\text { PBAC score } \\
\text { Mean } \pm S D\end{array}$ & $184.41 \pm 84.97$ & $83.77 \pm 55.46$ & $\mathbf{P}<\mathbf{0 . 0 0 1}$ \\
\hline 6. & $\begin{array}{l}\text { Hb(g/dl) } \\
\text { Mean } \pm S D\end{array}$ & $9.19 \pm 0.78$ & $10.5 \pm 0.88$ & $\mathbf{P}<\mathbf{0 . 0 0 1}$ \\
\hline & & & & \\
\hline
\end{tabular}

\section{Results}

A total of 50 patients were recruited and followed up at the Gynaecologic outpatient department after taking informed consent. Only 44 patients completed the full 6 months treatment. Figure 1 shows the details of patients excluded, recruited and treated.

The age and parity distribution is computed in Table 1 . The mean age of the patients were $34.34 \pm 6.45(20-50)$ years and parity $2(0-4)$. All the patients were of reproductive age group with regular cycles. Only 2 patients were of 45 years of age. $25 \%$ women were above the age of 40 years. There were only 2 (4.5\%) nulliparous women.

The characteristics and clinical presentation of the fibroids are summarised in Table 2. 75\% were solitary fibroids, $79.55 \%$ were intramural and only $11.36 \%$ were asymptomatic.

The volume of the fibroids mostly remained unaltered at the end of 6 months $(90.9 \%)$ and very few $(9.09 \%)$ increased in size. None of the fibroids reduced in size (Figure 2).

The outcome of treatment with ormeloxifene with regard to effect on fibroid volume, uterine volume, delta size, endometrial thickness and menstrual blood loss (PBAC and haemoglobin levels) at the end of 6 months has been summarized in Table 3 .
The drug did not affect the fibroid volume $(\mathrm{P}=0.074)$. It did not alter the volume of the normal myometrium i.e the delta volume $(\mathrm{P}=0.06)$. Thus, there was no statistically significant change in the uterine volume $(\mathrm{P}=0.054)$. However, ormeloxifene significantly reduced the endometrial thickness $(\mathrm{P}<0.001)$ and achieved significant lower PBAC score $(\mathrm{P}<0.001)$ after 6 months of therapy. In $10 / 44$ (22.72\%) patients there was amenorrhoea after 6 months. There was also statistically significant improvement in haemoglobin levels $(\mathrm{P}<0.001)$.

There were no major side effects. Mild nausea and vomiting were reported in $59.09 \%$ of subjects but it was not significant enough to stop the therapy.

At the end of the study 5 patients (11.36\%) underwent hysterectomy. This included the 4 patients in whom fibroid size increased and 1 patient who insisted on the operation due to persisting pain in lower abdomen.

\section{Discussion}

A safe yet effective medical therapy which could avoid surgical procedures in uterine fibroids is the need of the day. With various drugs being researched for the purpose, SERMS notably ormeloxifene with a convenient biweekly regimen and selective antiestogenic effect on endometrium and breast could be an effective treatment modality.

Our study showed that when prescribed for a short period of 6 months in uterine fibroids ormeloxifene significantly reduces mean blood loss by significantly decreasing the endometrial thickness without significantly affecting the mean fibroid volume, uterine or delta size.

The mean pretreatment fibroid volume was $22.81 \pm 36.03 \mathrm{cc}$. And the mean post treatment fibroid volume was $25.69 \pm 42.44 \mathrm{cc}$. The WMD 95\% CI being -2.88 (-6.05 to 0.29$)$. The $P$ value being 0.074 was not significant. The volume of fibroids remained unchanged in $90.9 \%$ women at the end of treatment. This is similar to a study with another SERM, raloxifene used in the dose of $180 \mathrm{mg} /$ day for 6 cycles, where $86.7 \%$ fibroids remained static [18]. This suggests that though SERMs did not decrease fibroid size they prevented further fibroid growth.

In another study with Raloxifene $(180 \mathrm{mg} / \mathrm{d})$ a significant reduction in fibroid volume with a mean Weighted Difference

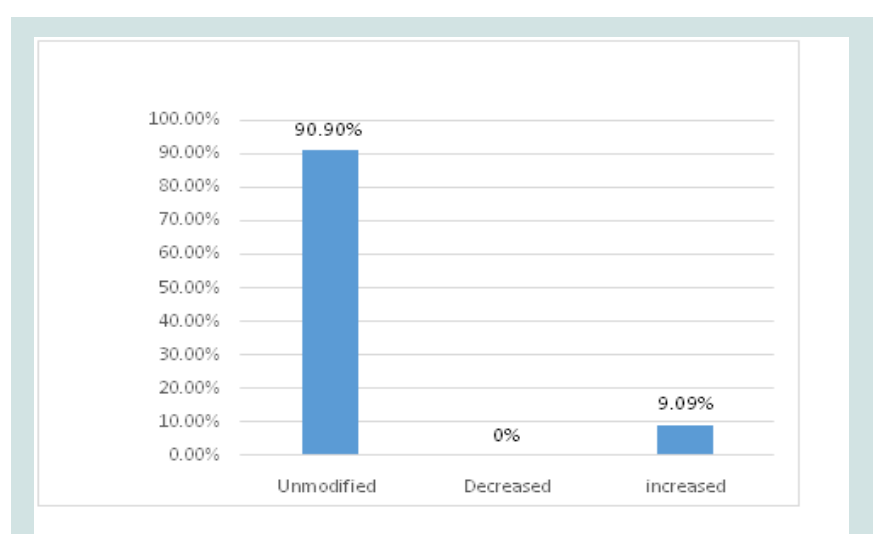

Figure 2: Change in leiomyoma sizes after 6 months of treatment. 
Citation: Dasgupta M, Karlo B, Biswas R, Bag T, Dutta S. Evaluation of the SERM Ormeloxifene in the Treatment of Uterine Fibroid in the Reproductive Age Group. J Syndromes. 2016;3(1): 5.

(WMD) 95\% C.I being -22.20 (-42.20 to -2.20) was achieved [27] This was possibly because the study group involved premenopausal subjects i.e. those with lower estrogen levels, where high doses of SERMS can inhibit leiomyoma growth but are ineffective in normally cycled women $[17,18]$.

This observation was reiterated by addition of Raloxifene 60 $\mathrm{mg}$ to $\mathrm{GnRh}$ analogue 25 where there was a significant reduction of leiomyoma, uterine and delta sizes but no difference in leiomyoma related symptoms. Thus it may be concluded that SERM administration induced a higher reduction of fibroid sizes in presence of low circulating estrogen.

Clinical studies with another SERM-Tamoxifen have shown unclear effect on uterine leiomyomas in humans [28-30]. However a more recent rat study has confirmed that the treatment with tamoxifen reduces the size of leiomyomas by $40-60 \%$. This action is due to inhibition of cell proliferation without a decrease in apoptotic index [16].

The uterine and delta size was unchanged in our study groupshowing that ormeloxifene has no effect on non-leiomyomatous tissue.

The menstrual blood loss was significantly reduced in our series. The mean pretreatment PBAC score for this group was $184.41 \pm 84.97$ which significantly decreased to $83.77 \pm 55.46$ post treatment $(\mathrm{P}<0.001)$. This was reflected in a statistically significant increase in mean hemoglobin level from $9.2 \mathrm{~g} / \mathrm{dl}$ to $10.5 \mathrm{~g} / \mathrm{dl}$ after 6 months $(\mathrm{P}<0.001) .95 \%$ confidence interval being -1.4614 to -1.1567 .

However, no significant clinical benefits in terms of rise in haemoglobin or improved PBAC scores were demonstrated in studies with raloxifene [18] in normally cycling women but definite improved PBAC scores were shown in women with low estrogen [17]

The significant reduction of endometrial thickness from pretreatment value of $7.99 \pm 1.16 \mathrm{~mm}$ to post treatment values of $7.12 \pm 1.15 \mathrm{~mm}$ of the study was probably the explanation for achieving lower blood loss and hence lower PBAC scores. Thus, the clinical improvement of menorrhagia together with achieving amenorrhoea in $22.72 \%$ women with fibroids appears to be an advantage of the SERM ormeloxifene over raloxifene.

After six cycles of ormeloxifene treatment, in only four women an increase in tumor size was detected, whereas in a high percentage of cases the leiomyoma size was unmodified. Indeed, it seems that the use of $60 \mathrm{mg}$ biweekly of ormeloxifene acts more on preventing tumoral growth than reducing the leiomyoma sizes.

Our findings may be explained on the basis of the different response and activity of the two Estrogen Receptors (ER) in the uterus, i.e. $\mathrm{ER} \alpha$ (predominantly present in endometrium) and $\operatorname{ER} \beta$ (in ovarian follicles). ER $\alpha$ binds to estrogens with high affinity and low capacity inducing activation of transcription, whereas ER $\beta$ binds to estrogens with low affinity and high capacity and inhibits transcription [31,32] The levels of both ER $\alpha$ and ER $\beta$ mRNA are higher in leiomyoma tissue. The concentrations of ER $\beta$ being 2- to 3-fold higher in leiomyoma in comparison with normal myometrium. There are ERa variants that lack E2 binding sites for posttranscriptional modification or a faulty translation of ERa mRNA [33].
Ormeloxifene binds with both ER subtypes, with more selectivity and higher affinity towards $\mathrm{ER} \alpha(8.8 \%)$ as compared to $\operatorname{ER} \beta(3 \%)$ [34]. Hence, as ERa receptor activity is low in fibroids ormeloxifene cannot reduce its size by antiestogenic effect. However, it effectively reduces the endometrial thickness where good numbers of ERa receptors are present.

The main limitation of our study was its short duration whereby clinical and anthropometric improvements were not evident. The absence of double blind placebo controlled method to eliminate information bias was not possible as we did not want to deny anybody treatment. Moreover, only standard $60 \mathrm{mg}$ biweekly dose of the drug was studied- possibly too low a dosage to reduce or revert the proliferative effect of serum E2 in normal ovulatory women. Also it was not possible to stratify patients according to fibroid size and response.

The strength of our study is that in our knowledge this is probably one of the earliest studies on the effect of the SERM ormeloxifene on fibroids with adequate power $(>80 \%)$. There are many studies on raloxifene and tamoxifen on fibroid but no studies with ormeloxifene [21] with the above study design.

However, it is intuitive that larger studies of bigger sample sizes and with different dosing schedules of ormeloxifene may open up a completely different strategy of medical therapy of uterine fibroids.

\section{Conclusion}

SERM such as ormeloxifene in standard biweekly dosage is effective in preventing further growth of uterine fibroids and reduces menstrual blood loss when prescribed for a short period of 6 months. Thus, it may be used as an interim treatment to delay operation especially in patients who need improvement in general condition. The drug does not have significant side effects and is available at a low cost. However, it role as the sole medical method in fibroid management needs to be assessed by more robust studies in future.

\section{References}

1. Steward EA (2001) Uterine fibroids. Lancet 357: 293-298.

2. Farber M, Conrad S, Heinrichs WL, Herrman WL (1972) Estradiol binding by fibroid tumors and normal myometrtium. Obstet Gynecol 40: 479-486.

3. Wilson EA, Yang F, Rees ED (1980) Estradiol and progesterone binding in uterine leiomyomata and in normal uterine tissues. Obstet Gynecol 55: 20-24.

4. Tamaya T, Fujimoto J, Okada H (1985) Comparison of cellular levels of steroid receptors in uterine leiomyomas and myometrium. Acta Obstet Gynecol Scand 64: 307-309.

5. Buttram VC Jr, Reiter RC (1981) Uterine leiomyomas: etiology, symptamology, and management. Fertil Steril 36: 433-445.

6. Otubu JA, Buttrum VC, Besch NF, Besch PK (1982) Unconjugated steroids in leiomyomas and tumor-bearing myometrium. Am J Obst Gynecol 143: 130133

7. Friedman AJ, Thomas PP (1995) Does low-dose combination ora contraceptive use affect uterine size or menstrual flow in premenopausal women with leiomyomas? Obstet Gynecol 85: 631-635.

8. Marshall LM, Spiegelman D, Goldman MB, Manson JE, Colditz GA, et al (1998) A prospective study of reproductive factors and oral contraceptive use in relation to the risk of uterine leiomyomata. Fertil Steril 70: 432-439.

9. Coutinho EM (1989) Gestrinone in the treatment of myomas. Acta Obstet 
Citation: Dasgupta M, Karlo B, Biswas R, Bag T, Dutta S. Evaluation of the SERM Ormeloxifene in the Treatment of Uterine Fibroid in the Reproductive Age Group. J Syndromes. 2016;3(1): 5.

Gynecol Scand Suppl 150: 39-46.

10. De Leo V, la Marca A, Morgante G (1999) Short-term treatment of uterine fibromyomas with danazol. Gynecol Obstet Invest 47: 258-262.

11. Kertel LM, Murphy AA, Morales AJ, Yen SS (1994) Clinical efficacy of the antiprogesterone RU486 in the treatment of endometriosis and uterine fibroids. Hum Reprod 9: 116-120.

12. Fiscella K, Eisenger SH, Meldrum S, Feng C, Fisher SG, et al. (2006) Effect of mifepristone for symptomatic leiomyomata on quality of life and uterine size: a randomized controlled trial. Obstet Gynecol 108: 1381-1387.

13. Donnez J, Tatarchuk TF, Bouchard P, Puscasiu L, Zakharenko NF, et al. (2012) Ulipristal acetate versus placebo for fibroid treatment before surgery. N Engl J Med 366: 409-420.

14. Donnez J, Tomaszewski J, Vázquez F, Bouchard P, Lemieszczuk B, et al (2012) Ulipristal acetate versus leuprolide acetate for uterine fibroids. N Eng J Med 366: 421-432.

15. Flierman PA, Oberye JJ, van der Hulst VP, de Blok S (2005) Rapid reduction of leiomyoma volume during treatment with $\mathrm{GnRH}$ antagonist ganirelix. BJOG 112: 638-642.

16. Walker CL, Burroughs KD, Davis B, Sowell K, Everitt Jl, et al. (2000) Preclinical evidence for therapeutic efficacy of selective estrogen receptor modulators for uterine leiomyoma. J Soc Gynecol Investig 7: 249-256.

17. Palomba S, Sammartino A, Di Carlo C, Affinito P, Zullo F, et al. (2001) Effect of raloxifene treatment on uterine leiomyomas in postmenopausal women. Fertil Steril 76: 38-43

18. Palomba S, Orio F Jr, Morelli M, Russo T, Pellicano M, et al. (2002) Raloxifene administration in premenopausal women with uterine leiomyomas: a pilot study. J Clin Endocrinol Metab 87: 3603-3608.

19. Singh MM (2001) Centchroman, a selective estrogen receptor modulator as a contraceptive and for the management of hormone- related clinical disorders. Med Res Rev 21: 302-347.

20. Dhananjay BS, Sunil Kumar Nanda (2013) The role of sevista in the management of dysfunctional uterine bleeding. J Clin Diagn Res 7: 132-134

21. Deng L, Wu T, Chen XY, Xie L, Yang J (2012) Selective estrogen receptor modulators (SERMs) for uterine leiomyomas. Cochrane Database Syst Rev 10: CD005287.

22. Makker A, Tandon I, Goel MM, Singh M, Singh MM (2009) Effect of ormeloxifene, a selective estrogen receptor modulator, on the biomarkers of the endometrial receptivity and pinopode development and its relation to fertility and infertility in Indian subjects. Fertil Steril 91: 2298-2307.

23. American College of Obstetricians and Gynecologists (2002) ACOG Practice Bulletin: Clinical Management Guidelines for Obstetrician-Gynecologists: Number 39, October 2002. Selective estrogen receptor modulators. Obstet Gynecol 39: 835-843.

24. Higham JM, O'Brien PM, Shaw RW (1990) Assessment of menstrual blood loss using a pictorial chart. Br J Obstet Gynecol 97: 734-739.

25. Palomba S, Orio F Jr, Russo T, Falbo A, Cascella T, et al. ( 2004) Long-term effectiveness and safety of $\mathrm{GnRH}$ agonist plus raloxifene administration in women with uterine leiomyomas. Hum Reprod 19: 1308-1314.

26. Sener AB, Seckin NC, Ozmen S, Gokmen O, Dogu N, et al. (1996) The effects of hormone replacement therapy on uterine fibroids in postmenopausal women. Fertil Steril 63: 354-357.

27. Jirecek S, Lee A, Pavo I, Crans G, Eppel W, et al. (2004) Raloxifene prevents the growth of uterine leiomyomas in premenopausal women. Fertil Steril 81: 132-136.

28. Lumsden MA, West CP, Baird DT (1989) Tamoxifen prolongs luteal phase in premenopausal women but has no effect on the size of uterine fibroids. Clin Endocrinol (Oxf) 31: 335-343.

29. Schwartz LB, Rutkowski N, Horan C, Nachtigall LE, Snyder J, et al. (1998) Use of transvaginal ultrasonography to monitor the effects of tamoxifen on uterine leiomyoma size and ovarian cyst formation. J Ultrasound Med 17: 699-703.

30. Sadan O, Ginath S, Sofer D, Rotmensch S, Debby A, et al. (2001) The role of tamoxifen in the treatment of symptomatic uterine leiomyomata-a pilot study. Eur J Obstet Gynecol Reprod Biol 96: 183-186

31. Paech K, Webb P, Kuiper GG, Nilsson S, Gustafsson J, et al. (1997) Differential ligand activation of estrogen receptors ERalpha and ERbeta at AP1 sites. Science 277: 1508-1510.

32. Kuiper GGJM, Carlsson B, Grandien K, Enmark E, Haggblad J, et al. (1997) Comparison of the ligand binding specificity and transcript tissue distribution of estrogen receptors alpha and beta. Endocrinology 138: 863-870.

33. Benassayag C, Leroy MJ, Rigourd V, Robert B, Honore JC, et al. (1999) Estrogen receptors (ERalpha/ERbeta) in normal and pathological growth of the human myometrium: pregnancy and leiomyoma. Am J Physiol 276(6 Pt 1): E1112-E1118

34. Blesson CS, Awasthi S, Kharkwal G, Daverey A, Dwivedi A (2006) Modulation of estrogen receptor transactivation and estrogen-induced gene expression by ormeloxifene-a triphenylethylene derivative. Steroids 71: 993-1000. 